\title{
REVIEW
}

\section{Chordoma: The Quest for Better Treatment Options}

\author{
Christopher R. Heery
}

To view enhanced content go to www.oncologytherapy-open.com

Received: November 23, 2015 / Published online: March 3, 2016

(c) The Author(s) 2016. This article is published with open access at Springerlink.com

\section{ABSTRACT}

Chordoma is an extremely rare cancer, with an incidence of about one case per million persons per year in the USA and Europe (about 300 and 450 cases per year, respectively). The estimated median overall survival of patients with chordoma is approximately 6-7 years, yielding a rough estimate of chordoma prevalence at about 2000 in the USA and 3000 in Europe. Primary tumor develops along the axial spine between the clivus and sacrum and develops from the residual embryonic notochord. Brachyury (T), a transcription factor required for normal embryonic development, is expressed in the notochord and overexpressed in almost all cases of chordoma. The primary treatment for chordoma is surgical excision with wide local margins, when possible. Radiotherapy also plays a significant role in the adjuvant setting and when surgery is not possible. Unfortunately, in the advanced and/or

C. R. Heery ( $\square)$

Laboratory of Tumor Immunology and Biology, Center for Cancer Research, National Cancer Institute, National Institutes of Health, Bethesda, MD 20892, USA

e-mail: heerycr@mail.nih.gov metastatic setting, where the role of surgery and/or radiation is less clear, treatment options are very limited. To date, there have been no randomized, controlled trials in chordoma that have resulted in defined agents of clinical benefit for systemic treatment. This review briefly describes the natural history and initial treatment of chordoma and focuses on treatment options for advanced disease and potential avenues of research that may lead to improved treatment options in the future.

Keywords: Brachyury; Chordoma; Erlotinib; Imatinib; Immunotherapy; Radiotherapy; Spine tumor; Surgery; Vaccine

\section{INTRODUCTION}

Chordoma is an extremely rare cancer, with an incidence of about one case per million persons per year in the USA (about 300 cases per year) [1]. Chordoma has been called "bone cancer" [2], but this designation is debatable based on histologic features, which are more consistent with its presumed tumor of origin, namely, the residual embryonic notochord tissue $[3,4]$. 
Designating chordoma as a "bone tumor" appears to be a holdover from the initial description of the disease by Virchow [5], but it was called into question soon thereafter by Ribbert [6], who coined the name "chordoma" based on its similarity to notochord tissue [7]. The relationship of chordoma to the notochord was strengthened by the finding that brachyury, a transcription factor found in notochord tissue and essential for embryonic development, is overexpressed in chordoma [3, 8]. Regardless of its historical designation, chordoma has unique histologic, radiographic, and clinical characteristics that call for chordoma-specific research to improve outcomes for patients with the disease. In this review, I briefly review the previously published natural history of the disease, including tumor characteristics, standard treatment paradigms, clinical management issues, and results of systemic treatment trials to date, to provide context for potential therapeutic targets and possible future treatment options.

\section{EPIDEMIOLOGY, PRESENTATION, AND DIAGNOSIS}

Chordoma is most commonly diagnosed between ages 50 and 60 , and it is more common in men than women, and rare in children [1]. Primary tumors develop along the axial spine, with approximately one-third of cases presenting in the clivus, mobile spine, and sacrum, respectively [1]. Disease presentation depends on tumor location and is related to the structures near which the tumor is growing. For example, patients with clival chordomas may present with headache, diplopia, or impairment of other cranial nerves, while those with sacral chordomas may present with low back or buttocks pain, neuropathy, and/or gait disturbance [7]. Patients may be diagnosed with large tumor masses in the sacrum due to the slow-growing nature of the disease, non-specific symptom profile, and a relatively large space for tumors to occupy before causing significant focal symptoms. Imaging findings that would point to chordoma include a mass along the axial spine, likely invading surrounding bone, which has a similar intensity to surrounding tissue on T1-weighted images, but appears hyperintense on T2-weighted images $[9,10]$. Unfortunately, due to the slow-growing nature of chordoma, which results in insidious, non-specific symptoms, diagnosis may be delayed for months or years. The median overall survival (OS) from time of diagnosis has been estimated at around 6 to 7 years [1], but the range of outcomes is very wide and may be related to prognostic markers, including treatment options at the time of diagnosis [11-13], as detailed below.

After surgical resection or initial biopsy, the diagnosis of chordoma is confirmed based on the classical (conventional) appearance of "sheets and cords of round to polygonal" tumor cells filled with occasionally large mucin-filled eosinophilic cytoplasm called physaliphorous cells [14]. Two less common chordoma variants are chondroid chordoma and dedifferentiated chordoma. Features of chondroid chordoma include the presence of "cartilaginous differentiation, not present in classical chordoma" [14]. Dedifferentiated chordoma occurs in a small subset of patients $(<5 \%)$; it has an aggressive course and its features are consistent with those of spindle cell (sarcomatoid) carcinoma under histologic review $[15,16]$. In cases where the diagnosis is not clear, staining for nuclear expression of brachyury distinguishes chordoma from tumors with similar morphologic features $[8,17,18]$. 


\section{TREATMENT AND INITIAL PROGNOSIS}

In 2015, the Chordoma Foundation and its advisors published a global consensus based on the input of world experts from the fields of medical oncology, radiation oncology, neurosurgery, and orthopedic surgery during the 2013 European Society for Medical Oncology annual meeting [19]. Practicing clinicians should use these guidelines when initially seeing a patient with chordoma, but the importance of patients being seen by a dedicated multidisciplinary team with experience in this rare disease cannot be overstated.

Surgery is the mainstay of treatment for primary and/or recurrent chordoma when feasible, and the outcome of surgery is closely related to the expected outcome for a given patient. Surgical techniques are specific to tumor site, but in general, the goal is to achieve a local excision with clear margins. The surgical management of chordoma has been discussed in detail in other recent reviews $[2,7,20]$ and thus will not be a focus of this review. However, multiple retrospective analyses have demonstrated the impact of surgery on prognosis [21-23]. In clival chordoma, though, there is evidence that aggressive resection may actually be the more cautious approach [13] because wide local excision is commonly not an option [22].

Radiotherapy also plays a key role in the management of patients with localized chordoma, particularly in the adjuvant setting after full resection or subtotal resection and as the primary treatment in unresectable disease. One series from Choy et al. indicated that the use of adjuvant radiotherapy was the most important variable influencing time to progression [13]. A research group from
Massachusetts General Hospital demonstrated excellent disease control with adjuvant high-dose radiotherapy after surgery in primary tumors after resection, but poor outcomes in recurrent disease [12]. This group went on to show reasonable tumor control with high-dose proton or photon radiotherapy in patients with primary, unresected chordoma, with 5-year OS and local progression-free survival (PFS) of $78.1 \%$ and $79.8 \%$, respectively [24]. The same group demonstrated very low recurrence rates in patients with localized spinal chordoma treated with high-dose radiotherapy, with the exception of locally recurrent chordomas, which had a 5-year recurrence rate of $50 \%$ [25]. Because proton-beam therapy is capable of delivering high doses of radiotherapy to focal targets, it has advantages over photon therapy. However, it is not clear that, at equivalent doses, proton therapy has any advantage over photon therapy in terms of disease control or the likelihood of symptom control.

Surgery, when feasible, should aim for margin-negative resection without penetration of the capsule, with adjuvant high-dose radiotherapy for optimal local tumor control [19]. Because this outcome is not possible for most patients, prediction of clinical outcome is very difficult for a given patient at the time of initial management. Patients with residual disease after surgery or unresectable disease at the time of diagnosis should consider high-dose radiotherapy at a center with expertise in delivering such doses for chordoma. An important surgical aspect of the tumor is related to its histology. These tumors contain gelatinous material that can spill into the resection cavity even with careful planning, and recurrence often occurs at the margins of the resected tumor. These characteristics of chordoma reinforce the importance of 

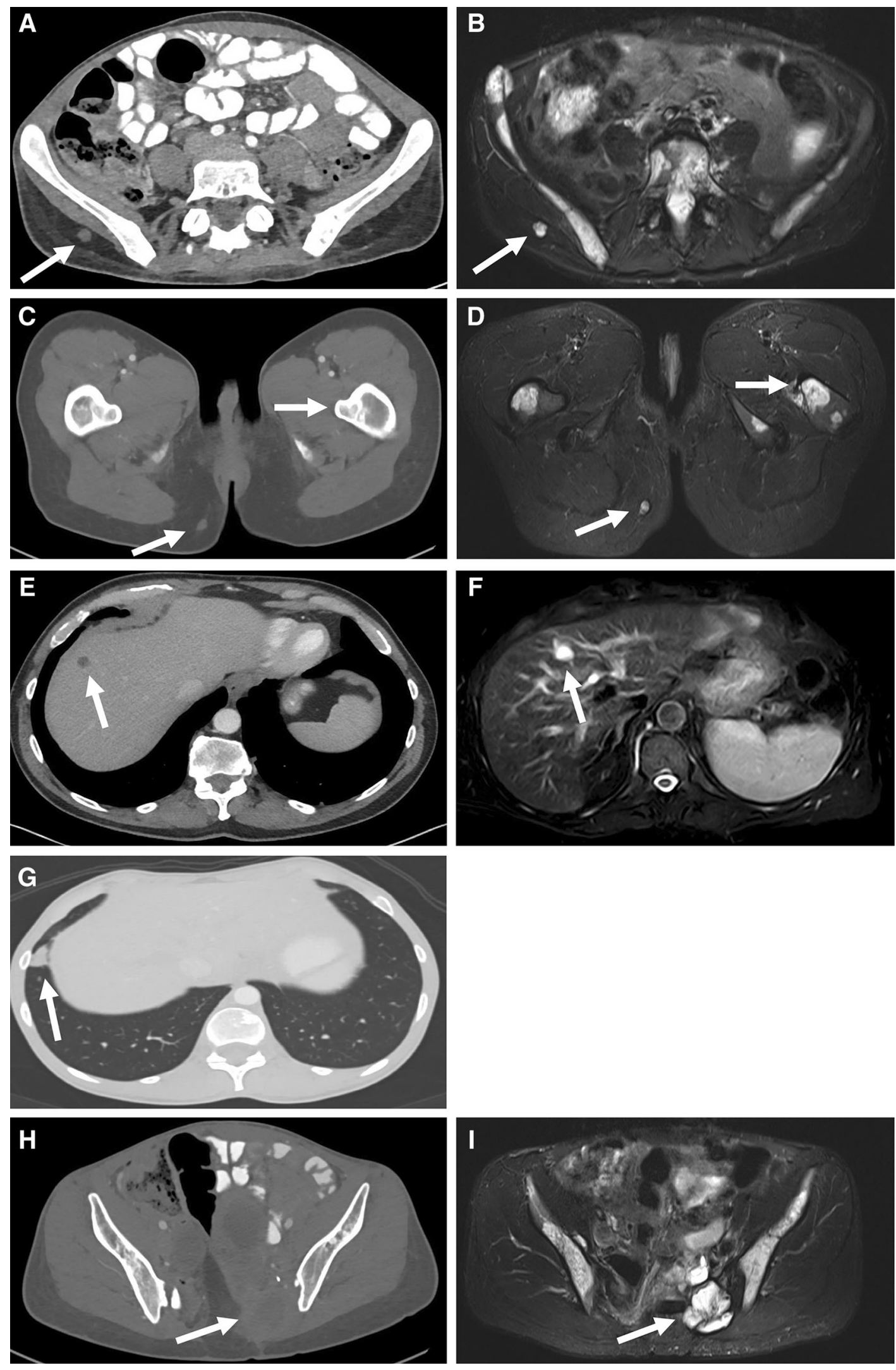
4Fig. 1 Imaging of localized and metastatic chordoma lesions. Imaging characteristics of chordoma lesions are specific in various metastatic locations. In some cases, a lesion may not be well visualized on computed tomography (CT) images, but may be easily seen on magnetic resonance imaging (MRI) scans, or vice versa. a Subcutaneous metastatic lesion is reasonably well seen on contrast-enhanced CT (white arrow). b In a T2-weighted [(Short-TI Inversion Recovery (STIR)] MRI sequence, the lesion glows bright (white arrow) in contrast to surrounding tissue. c Subcutaneous lesion is noted (white arrow, lower left), but bone lesions are not well visualized (upper right). d Subcutaneous lesion (white arrow, lower left) is easily seen and bone invasion (white arrow, upper right) is also readily visible. e Liver lesions (white arrow) appear very similar to liver cysts in metastatic chordoma. f T2-weighted (STIR) MRI images of the liver confirm that the cystic-appearing lesion (white arrow) is consistent with chordoma. g Lung lesions are easily seen on contrast-enhanced CT (white arrow); little is gained from MRI scans of these same lesions. h Primary tumor site in the lower spine or sacrum (white arrow) can be difficult to assess by CT due to similar density of the lesion and surrounding tissue. I T2-weighted (STIR) MRI images clearly delineate chordoma mass (white arrow) from surrounding structures

consulting an experienced, multidisciplinary team for initial treatment. In fact, a recent retrospective analysis suggested that preoperative radiation may reduce the risk of surgical-field contamination [26]. Patients should be encouraged to seek the assistance of advocacy groups, such as the Chordoma Foundation (http://www.chordomafoundation. org/), for recommendations of treatment centers for their specific situation.

\section{RECURRENT AND METASTATIC DISEASE}

Chordoma is often considered to be a slow-growing disease with low metastatic potential, but this description may give the wrong impression of its disease course in the advanced setting. Chambers et al. reported that $30 \%$ of patients developed metastatic disease, with a predominance of lesions occurring in patients with non-clival chordoma [27]. Kishimoto et al. described a similar incidence of metastatic disease in a group of 198 patients [9]. Other studies have described a wide range of observed metastatic disease. However, it is possible that these retrospective analyses underrepresent the true incidence of metastatic chordoma. Sites of metastatic disease are widely variable and include subcutaneous tissue, liver, lung, lymph nodes, and bone [22, 27] (Fig. 1). Because some sites of metastatic chordoma may not be well visualized by an imaging modality that can easily detect other sites of metastasis (Fig. 1), or because clinical evaluation commonly focuses on local recurrence, sites of metastatic disease can easily be missed. However, this may not be an issue of great significance in most cases because local recurrence is still the major cause of morbidity and mortality [22]. In older series, OS in patients with metastatic disease has been reported as approximately 1 year [28], but more recent series have indicated a median OS closer to 3 years $[22,29]$. This apparent shift in survival from the time of detection of metastatic disease may be due to detection bias, in which metastatic lesions are identified earlier with improved imaging modalities and more thorough evaluation. Alternatively, the difference could be due to improved treatment methods over time.

\section{SYSTEMIC TREATMENT}

To date, there has been no randomized, controlled trial of a therapeutic agent in locally advanced and/or metastatic chordoma. Perhaps owing to the lack of clear historical control data in this population, there also has not been a study that has clearly defined 
treatment benefit for patients with advanced chordoma. The combination of the rarity of the disease and the diversity of upfront clinical management practice makes clinical trial design and enrollment difficult. Table 1 summarizes data from clinical trials of systemic treatment. Imatinib is the most thoroughly evaluated therapeutic agent in chordoma, based on the expression of platelet-derived growth factor beta (PDGFB) or its receptor (PDGFRB). Imatinib, which is best known as an inhibitor of the BCR-ABL gene fusion product, which is a constitutively active tyrosine kinase, has off-target effects, including the inhibition of PDGFRB [30, 31]. In a single-arm phase II study, Stacchiotti et al. observed a radiographic response rate of only 1 of 50 patients (2\%) as measured by the Response Evaluation Criteria in Solid Tumors (RECIST; 30\% decrease in sum of longest diameters), despite stable disease in 35 of 50 patients (70\%). The median PFS in the study was 9 months [32], but it is not clear how this would compare with no treatment in a similar cohort. In a separate retrospective analysis, 17 of 17 patients with advanced disease and PDGFR expression experienced stable disease, but no radiographic responses were observed [33]. Imatinib, though commonly used in clinical practice [34], is not approved by the U.S. Food and Drug Administration (FDA), or by any other regulatory agency, for the treatment of chordoma.

Based on preclinical evidence of the role of epidermal growth factor receptor (EGFR) in chordoma pathogenesis [35], Stacchiotti et al. performed a single-arm phase II clinical trial evaluating lapatinib (a dual inhibitor of EGFR and Her2) in subjects with advanced EGFR-overexpressing chordomas. Eighteen patients were enrolled and treated, and six (33.3\%) experienced a response based on the
Choi radiographic criteria. Median PFS in this study was 6 months by the Choi criteria and 8 months by the RECIST guideline [36]. Further attempts to target EGFR in chordoma include a case report which described a radiographic partial response using erlotinib alone [37], and another case series which described stable disease in three patients when erlotinib was used in combination with bevacizumab [38]. EGFR has also been targeted via the combination of the monoclonal antibody cetuximab and gefitinib, a tyrosine kinase inhibitor of EGFR. In two separate case reports, individual patients achieved partial radiographically defined responses $[39,40]$.

Bompas et al. evaluated sorafenib, a multikinase inhibitor, in an open-label, multicenter, single-arm phase II clinical trial. Sorafenib targets a number of tyrosine kinases that are overexpressed in chordoma, including vascular endothelial growth factor (VEGF), PDGF, EGFR, and c-KIT [41]. The goal of the study was to determine the 9-month PFS, as well as to describe other clinical outcomes. After a median 8.7-month follow-up, the median PFS was not reached, median OS was not reached, and there was one partial radiographic response according to the RECIST 1.1 guideline. The 9-month PFS was 73\%. Adverse events related to sorafenib were similar to those seen historically in other disease settings, which include grade 3 hand-foot syndrome (18.5\%), diarrhea (18.5\%), hypertension (18.5\%), weight loss (14.8\%), and fatigue $(11.1 \%)$. Notably, there is no historical control for trials such as this one in advanced chordoma and due to the heterogeneity of the patient population in the advanced setting, it is difficult to interpret PFS in single-arm studies like this. It is even more difficult to interpret PFS in the setting of significant toxicities, such as those caused by sorafenib. In the opinion of this author, the radiographic response is interesting 
Table 1 Summary of systemic therapy data

\begin{tabular}{|c|c|c|c|c|c|}
\hline Therapy & Target & $\begin{array}{l}\text { Number } \\
\text { of } \\
\text { chordoma } \\
\text { patients }\end{array}$ & Reported results & Study design & References \\
\hline Imatinib & PDGFR & 50 & $\begin{array}{l}1 \text { PR (RECIST); } 35 \text { SD; } \\
\text { median PFS = } 9 \text { months } \\
\text { (RECIST) }\end{array}$ & $\begin{array}{l}\text { Single-arm phase } \\
\text { II trial }\end{array}$ & $\begin{array}{l}\text { Stacchiotti } \\
\text { et al. [32] }\end{array}$ \\
\hline Imatinib & PDGFR & 17 & $0 \mathrm{PR} ; 17 \mathrm{SD}$ & Case series & $\begin{array}{l}\text { Ferraresi et al. } \\
\text { [33] }\end{array}$ \\
\hline Lapatinib & EGFR & 18 & $\begin{array}{l}13 \text { SD; } 6 \text { PR (Choi); } 0 \text { PR } \\
\text { (RECIST); median } \\
\text { PFS }=8 \text { months } \\
\text { (RECIST) }\end{array}$ & $\begin{array}{l}\text { Single-arm phase } \\
\text { II trial }\end{array}$ & $\begin{array}{l}\text { Shalaby et al. } \\
\qquad[35]\end{array}$ \\
\hline Erlotinib & EGFR & 1 & $1 \mathrm{PR}$ & Case report & $\begin{array}{l}\text { Singhal et al. } \\
\text { [37] }\end{array}$ \\
\hline Erlotinib + bevacizumab & EGFR, VEGF & 3 & $3 \mathrm{SD}$ & Case report & $\begin{array}{l}\text { Asklund et a. } \\
\text { [38] }\end{array}$ \\
\hline Cetuximab + gefitinib & EGFR & 1 & $1 \mathrm{PR}$ & Case report & Hof et al. [39] \\
\hline Cetuximab + gefitinib & EGFR & 1 & $1 \mathrm{PR}$ & Case report & $\begin{array}{l}\text { Linden et al. } \\
\text { [40] }\end{array}$ \\
\hline Sorafenib & Multiple & 27 & $\begin{array}{l}1 \text { PR (RECIST); 9-month } \\
\quad \text { PFS = 73.0\%; } \\
\text { 12-month OS = } 86.5 \%\end{array}$ & $\begin{array}{l}\text { Single-arm phase } \\
\text { II trial }\end{array}$ & $\begin{array}{l}\text { Bompas et al. } \\
\text { [41] }\end{array}$ \\
\hline 9-Nitro-camptothecin & $\begin{array}{l}\text { Topoisomerase } \\
\text { I }\end{array}$ & 15 & $\begin{array}{l}1 \mathrm{PR} \text { (RECIST); median } \\
\text { PFS = } 9.9 \text { months }\end{array}$ & $\begin{array}{l}\text { Single-arm phase } \\
\text { II trial }\end{array}$ & $\begin{array}{l}\text { Wilhelm et al. } \\
\text { [42] }\end{array}$ \\
\hline Thalidomide & Multiple & 1 & $1 \mathrm{PR}$ & Case report & $\begin{array}{l}\text { Chay et al. } \\
\text { [44] }\end{array}$ \\
\hline $\begin{array}{l}\text { GI-6301 (recombinant } \\
\text { yeast-brachyury } \\
\text { vaccine) }\end{array}$ & Brachyury & 11 & $\begin{array}{l}1 \mathrm{PR} \text { (RECIST); } 1 \text { mixed } \\
\text { response (RECIST); } \\
\text { median } \\
\text { PFS }=8.3 \text { months }\end{array}$ & Phase I trial & $\begin{array}{l}\text { Heery et al. } \\
{[65]}\end{array}$ \\
\hline
\end{tabular}

Table is modified with permission from http://www.chordomafoundation.org/systemic-therapy/

$P R$ partial response, $P F S$ progression-free survival, RECIST Response Evaluation Criteria in Solid Tumors, SD stable disease

and deserves further study, but any future study should have an active comparator arm to determine the role of sorafenib, given its adverse-event profile.

A single-arm phase II study of 9-nitro-camptothecin, an oral topoisomerase I inhibitor, enrolled 15 patients with advanced chordoma. One of 15 patients (7\%) had an objective radiographic response, and the median PFS was 9.9 months [43]. Thalidomide has also been reported to induce a radiographic response in one case report [44]. Despite 
intermittent reports of activity with various agents, there is no clear standard of treatment in the advanced disease setting.

It is unclear if the agents described herein have an impact on clinical outcomes in patients other than those who have responses, because there is no clear historical control or randomized control arm comparator for PFS in the single-arm studies performed to date. The heterogeneity of clinical outcomes in the advanced disease setting, paired with the rarity of the disease, makes the path to drug registration unclear unless an agent induces objective responses in a larger proportion of patients [45].

\section{POTENTIAL FUTURE TREATMENTS}

\section{Brachyury}

In addition to being a diagnostic marker for chordoma, brachyury may be a potential target for treatment $[46,47]$. Brachyury appears to be an oncogenic driver of chordoma [3, 48]. The non-synonymous presence of the rs2305086 single nucleotide polymorphism was associated with increased risk of chordoma in one series [49], yet in another study, in Chinese patients, no such association was found [50].

It was previously thought that brachyury was specific only to chordoma and could be used, primarily, as a diagnostic tool $[8,51]$. While nuclear brachyury expression remains useful to distinguish chordoma from tumors with similar morphologic features, it has become clear that brachyury is also expressed in other tumors, including epithelial tumors [34, 52-55]. Our group has developed a rabbit monoclonal antibody [56] that is highly specific for brachyury staining. In a recent analysis of $>5000$ tumors, nuclear brachyury expression was present in $>98 \%$ of chordomas analyzed
[17]. This study only evaluated nuclear staining and did not analyze cytosolic expression of brachyury, as has been described in other tumors [56].

In epithelial tumors, brachyury expression drives epithelial-to-mesenchymal transition, inducing stem-like features such as migration, invasiveness, and resistance to conventional therapy [57-59]. In retrospective analyses of cohorts of patients with prostate [52], colorectal [53], breast [54], lung [55], and hepatocellular carcinoma [34], brachyury expression has been associated with poor prognosis. Interestingly, chordoma cells express many of the markers of mesenchymal cells typically induced with brachyury upregulation in other tumor types, including decreased e-cadherin levels and increased n-cadherin [60] and vimentin levels [61].

Historically, transcription factors have been considered "undruggable" [62] with targeted or standard cytotoxic agents, but other potential avenues for targeting brachyury have been proposed, including small inhibitory RNA, epigenetic modulation, and immune-based therapy $[63,64]$. To date, the only attempts to target brachyury have been with two therapeutic cancer vaccines. Our group recently completed a phase I trial of GI-6301 (recombinant yeast-brachyury vaccine) which enrolled 11 patients with advanced chordoma (NCT01519817) [65]. One patient had a confirmed radiographic partial response (PR) by the RECIST guideline, and a second had a mixed response; the median PFS in the chordoma group was 8.3 months. The vaccine induced brachyury-specific $\mathrm{T}$ cell responses in both the majority of all patients enrolled and the subset of patients enrolled with chordoma. There were no significant toxicities related to the vaccine [65]. Notably, the two patients with evidence of tumor shrinkage both had 
radiotherapy within 3.5 months of being enrolled on study. Given the low likelihood of radiographic response with radiotherapy alone in the advanced disease setting, our hypothesis was an immunomodulatory effect of radiotherapy on chordoma cells which resulted in an increased responsiveness to $T$ cell-mediated killing. Hodge et al. described a similar effect in other tumor cell lines [66-68].

Another phase I study of a vaccine targeting brachyury has recently completed accrual (NCT02179515). This vaccine is composed of a modified vaccinia virus Ankara (MVA) vector containing the transgene for brachyury and three costimulatory molecules (designated TRICOM).

\section{Mucin 1 and Carcinoembryonic Antigen}

A majority of chordoma cases from historical series express mucin 1 [MUC1 or epithelial membrane antigen (EMA)] [61]. Immunohistochemistry (IHC) studies have also identified carcinoembryonic antigen on chordoma cells in a lower percentage (3 of 14, $21 \%$ ) of cases [61]. Both of these targets can also be targeted immunologically with therapeutic cancer vaccines $[69,70]$ and may be candidates for future clinical trials.

\section{Survivin}

Survivin is another protein associated with poor prognosis and metastatic potential in other tumor types [71-76]. It is a member of the inhibitor of apoptosis (IAP) gene family. Similar to brachyury, it is rarely or never expressed in normal adult tissue, but it is found in many tumor cell types, including lung, colon, breast, prostate, and pancreatic cancer cells [77]. Chen et al. first described survivin expression in 21 of $30(70 \%)$ sacral chordoma samples analyzed by
IHC. Interestingly, these authors identified an association between survivin expression, which was mainly cytoplasmic, and the likelihood of both recurrence and local invasion at the time of surgery. Survivin did not correlate with any other demographic variable analyzed in that study [78].

Froehlich et al. then explored the function of survivin in chordoma cells [79] and evaluated survivin expression in 50 chordoma cases (34 primary and 16 recurrent) from 44 patients using IHC. Twenty-three of 34 (68\%) primary chordoma cases and 16 of 16 recurrent chordomas stained positive. Interestingly, of the positive-staining primary cases, only one had nuclear expression (others only had cytoplasmic staining), but all cases of recurrent chordoma were positive for nuclear staining. Three of three chordoma cell lines showed nuclear and cytoplasmic staining. There was no relationship between survivin expression and any of the demographic variables tested. The investigators then silenced survivin in the chordoma cell line using YM155 (sepantronium bromide), a survivin inhibitor. The treatment reduced survivin protein expression and increased markers of apoptosis. Based on their findings, the authors suggested that YM155, which has been demonstrated to be safe in other diseases [80-82], could be a potential therapeutic agent for use in chordoma [79].

\section{MicroRNA-Focused Approaches}

MicroRNAs (miRNAs) are small, noncoding, single-stranded segments of endogenous RNA, 19-25 nucleotides in length, that are capable of controlling gene expression through binding and thus preventing messenger RNA (mRNA) translation [83]. Because these segments of miRNA are not translated directly into protein, their role is mainly to regulate the expression of 
mRNA. It has been hypothesized that miRNA may have an important role in the dysregulation that occurs in human cancers; consequently, the manipulation of miRNAs may become a therapeutic intervention in the future. In recent years, many groups have investigated the potential role of miRNA in chordoma, and some interesting patterns of expression have emerged. A number of research groups have taken additional steps to demonstrate that increasing or decreasing certain miRNAs can have downstream effects on the expression of gene products thought to be important in the growth and progression of chordoma.

Duan et al. published the results of an initial study in which they evaluated and compared the expression of miRNA in human chordoma tissue samples and chordoma cell lines to that in normal tissues [84]. These authors found similar expression profiles of miRNA in chordoma cell lines and chordoma tissue samples. Additionally, 21 miRNA genes were differentially expressed between normal human tissue and the chordoma cell lines and chordoma tissue samples, including decreased expression of miRNA-1 and miRNA-206. Of these findings, perhaps the most interesting is the decreased expression of miRNA-1 in chordoma tissue and cell lines, which is a pattern seen in other sarcomas and epithelial malignancies. The authors also observed overexpression of Met and HDAC4 in the miRNA-1-deficient chordoma cells and tissue and went on to demonstrate that transfection of cell lines with miRNA-1 could suppress Met expression and decrease chordoma cell proliferation in vitro, leading them to suggest that miRNA-1 could be a candidate for therapeutic intervention in the future [84]. Later work by the same group confirmed that miRNA-1 is downregulated in $93.7 \%$ of chordoma tissues and has an inverse correlation with Met expression [85], which appears to occur downstream through control of the Slug gene in chordoma cells [86].

In a similar study, Long et al. evaluated the differential expression of miRNA and mRNA in chordoma versus notochord tissues [87]. Their microarray analysis identified differential expression of 33 miRNAs and 2791 mRNAs. Interestingly, 911 mRNAs were connected to signaling pathways regulated by miRNAs. These investigators found that the mitogen-activated protein kinases (MAPK) pathway was augmented in the chordoma tissue, which may have been influenced by suppressed expression of regulator miRNA associated with this pathway, including miRNA-149-3p, miRNA-663a, miRNA-1908, miRNA-2861, and miRNA-3185. In addition to the MAPK pathway, a number of other signaling pathways were found to be upregulated in chordoma, including those of transforming growth factor beta (TGF $\beta)$, Wnt, p53, ErbB, Notch, Jak-STAT, T-cell receptor signaling, mechanistic target of rapamycin (mTOR), and gonadotropin-releasing hormone (GnRH), among others. Perhaps most notably, six genes associated with Notch signaling were upregulated, indicating that this may be a pathway of interest for therapeutic intervention in future studies. Finally, the authors identified a link to suppressed miRNAs (miRNA-1228, miRNA-2861, miRNA-762) and pathway expression of genes related to ossification, which may be another potential therapeutic target in the future.

Further work by other groups has identified a number of potentially important differential expression patterns of miRNA in chordoma relative to normal tissue. These include mRNA-31, which has an apoptotic effect on chordoma cells by downregulating the 
expression of c-MET and radixin [88], miRNA-608 and miRNA-34a, which regulate EGFR, MET, and Bcl-xL [89], miRNA-10a and miRNA-125a, which were associated with adenosine deaminase acting on RNA expression [90], and miRNA-140-3p [91], miRNA-155 [92], and miRNA-1237-3p [93], which appear to be indicators of poor prognosis in retrospective analyses of chordoma samples.

The clinical utility of miRNA as a therapeutic target will depend heavily on the identification of a reliable delivery mechanism to tumor tissue in patients.

\section{Immune Checkpoint Inhibition}

Part of the complicated interaction between the immune system and tumor cells includes a normally occurring feedback loop thought to play a role in preventing autoimmunity. When a $\mathrm{T}$ cell is activated against an antigen, it upregulates programmed cell death receptor-1 (PD-1) and begins to secrete type 1 cytokines, including interferon-gamma (IFN- $\gamma$ ). In response to the cytokine secretion of activated $\mathrm{T}$ cells, normal human tissue will respond (via IFN- $\gamma$ receptor signaling) by upregulating programmed cell death ligand-1 (PD-L1). The binding of PD-L1 to PD-1 completes a feedback loop which causes suppression of the activated $\mathrm{T}$ cell, thereby preventing $\mathrm{T}$ cell-mediated damage of normal human cells and, consequently, autoimmunity. In many cancers, tumor cells also employ this system, which prevents $\mathrm{T}$ cell-mediated killing of tumor cells, even when an active immune response is present against the tumor. Blockade of this interaction with monoclonal antibodies designed to bind to PD-1 or PD-L1 has proven to be an effective antitumor strategy in a subset of patients with many different tumors [94-97].
A natural question is whether this strategy might be useful in the systemic treatment of advanced chordoma.

Two analyses of PD-L1 expression by groups at Johns Hopkins and Mass General, respectively, found slightly different expression patterns. The researchers at Johns Hopkins found that three of the six cases studied had infiltrating lymphocytes with PD-1 expression within the tumor lesion, but they did not find any tumor cells expressing PD-L1. However, they did find PD-L1 expression on tumor-infiltrating macrophages and tumor-infiltrating lymphocytes [98]. In contrast, the researchers at Mass General found PD-L1 expression in nine human tissue samples, but were unclear which cells expressed PD-L1, making the results somewhat more difficult to interpret [99]. In chordoma cell lines, both groups observed that PD-L1 expression can be induced in response to IFN- $\gamma$ or other pro-inflammatory cytokines. This finding indicates that the generation of an active immune response against chordoma in vivo (for example, via vaccine) could be complemented with PD-1/L1 inhibition, creating another potential therapeutic option in the future.

\section{Temozolomide}

$\mathrm{O}^{6}$-Methylguanin-DNA-methyltransferase (MGMT) promoter methylation status in chordoma was reported for the first time in a recent publication by Marucci et al. [100] These authors observed MGMT promoter methylation, which is known to predict the efficacy of temozolomide in glioblastoma, in four of $15(27 \%)$ cases of recurrent clival chordoma. The MGMT promotor was not methylated in any of 15 patients with clival chordoma who did not have a recurrence after a 
median follow-up of 8.5 years. Based on these findings, the authors suggest that patients with MGMT promotor methylation at the time of surgery could be considered for temozolomide therapy on the basis of its increased efficacy in glioblastoma when MGMT promotor methylation is present [101].

\section{Histone Deacetylase Inhibition}

Lee et al. recently demonstrated the potential role of histone deacetylase inhibition (HDACi) to overcome resistance to PDGFR inhibition mediated by the loss of heterozygosity of phosphatase and tensin homolog (PTEN). Indeed, in their study it appeared that HDACi diminished the aggressive phenotype seen in tumor cells with aberrant PTEN expression [102]. Other groups have suggested that HDACi may play a role in epigenetic modulation [103-105]. Given the significant role of the transcription factor brachyury in chordoma, agents like HDACi could potentially have an indirect effect on gene expression via epigenetic modulation. This is an area that should be explored in future clinical trials.

\section{Hypofractionated Radiotherapy}

Yamada et al. have pioneered the use of hypofractionated radiotherapy for chordoma, first showing that it was feasible [106] and then evaluating its efficacy [107]. Of 24 treated patients enrolled in their study, 23 (95\%) showed evidence of clinical benefit (stable disease or tumor shrinkage) on serial imaging. The greatest benefit was seen when a high-dose single fraction was delivered to a primary tumor. However, disease control has also been accomplished with multiple fractions at slightly lower doses in primary and recurrent tumors [106].

\section{CONCLUSIONS}

The initial management of chordoma is fairly well defined. Patients should have maximal tumor debulking and adjuvant high-dose radiotherapy when possible. When surgery is not possible, high-dose radiotherapy achieves reasonable disease control in most cases. However, the majority of patients are not eligible for optimal therapy, and most of these will have disease recurrence. In most cases, recurrent disease will lead to death along variable timelines. As a result, there is an urgent need for therapeutic options capable of controlling or shrinking tumors. To date, evaluations of systemic therapies have been limited to single-arm studies or case reports. Unfortunately, despite rational selection of agents based on potential therapeutic targets identified by extensive preclinical work, radiographic response rates have been very low. Thus, the impact of these agents cannot be fully assessed, which has precluded their approval for use in advanced chordoma by the FDA or other regulatory agencies. Additional therapeutic targets continue to emerge, including brachyury, survivin, and others not described here. The recent activity seen in other tumor types treated with immunotherapy suggests that therapeutic cancer vaccines, immune checkpoint inhibitors, or a combination of these agents may be potential therapeutic options for chordoma. Careful selection of patient populations and endpoints will be required to definitively demonstrate efficacy and increase the armamentarium for physicians treating this rare tumor.

\section{ACKNOWLEDGMENTS}

No funding or sponsorship was received for publication of this article. The named author meets the International Committee of Medical 
Journal Editors (ICMJE) criteria for authorship for this manuscript, takes responsibility for the integrity of the work as a whole, and has given final approval for this version to be published. The author thanks Dr. Jeffrey Schlom for his review of this manuscript and thoughtful suggestions, and Bonnie L. Casey and Debra Weingarten for editorial assistance in the preparation of the manuscript.

Disclosures. Christopher R. Heery is an investigator on the studies mentioned involving brachyury-targeting vaccines. He has no financial interest in any agent mentioned in this review article.

Compliance with Ethics Guidelines. This review is based on previously conducted studies and does not involve any new studies or data from unpublished studies of human or animal subjects performed by the author.

Open Access. This article is distributed under the terms of the Creative Commons Attribution-NonCommercial 4.0 International License (http://creativecommons.org/licenses/ by-nc/4.0/), which permits any noncommercial use, distribution, and reproduction in any medium, provided you give appropriate credit to the original author(s) and the source, provide a link to the Creative Commons license, and indicate if changes were made.

\section{REFERENCES}

1. McMaster ML, Goldstein AM, Bromley CM, Ishibe N, Parry DM. Chordoma: incidence and survival patterns in the United States, 1973-1995. Cancer Causes Control. 2001;12:1-11.

2. Chugh R, Tawbi H, Lucas DR, Biermann JS, Schuetze SM, Baker LH. Chordoma: the nonsarcoma primary bone tumor. Oncologist. 2007;12:1344-50.
3. Shen J, Li CD, Yang HL, et al. Classic chordoma coexisting with benign notochordal cell rest demonstrating different immunohistological expression patterns of brachyury and galectin-3. J Clin Neurosci. 2011;18:96-9.

4. Salisbury JR, Deverell MH, Cookson MJ, Whimster WF. Three-dimensional reconstruction of human embryonic notochords: clue to the pathogenesis of chordoma. J Pathol. 1993;171:59-62.

5. Virchow RL. Untersuchungen ueber die Entwicklung des Schaedelgrundes. G Rimer, Berlin; 1857.

6. Ribbert H. Uber die Ecchondosis physaliphora sphenooccipitalis. Centralbl Allg Pathol Anat. 1894;5:457-61.

7. Walcott BP, Nahed BV, Mohyeldin A, Coumans JV, Kahle KT, Ferreira MJ. Chordoma: current concepts, management, and future directions. Lancet Oncol. 2012;13:e69-76.

8. Vujovic S, Henderson S, Presneau N, et al. Brachyury, a crucial regulator of notochordal development, is a novel biomarker for chordomas. J Pathol. 2006;209:157-65.

9. Kishimoto R, Omatsu T, Hasegawa A, Imai R, Kandatsu S, Kamada T. Imaging characteristics of metastatic chordoma. Jpn J Radiol. 2012;30:509-16.

10. Llauger J, Palmer J, Amores S, Bague S, Camins A. Primary tumors of the sacrum: diagnostic imaging. AJR Am J Roentgenol. 2000;174:417-24.

11. Jahangiri A, Chin AT, Wagner JR, et al. Factors predicting recurrence after resection of clival chordoma using variable surgical approaches and radiation modalities. Neurosurgery. 2015;76:179-85 (discussion 85-6).

12. Park L, Delaney TF, Liebsch NJ, et al. Sacral chordomas: Impact of high-dose proton/ photon-beam radiation therapy combined with or without surgery for primary versus recurrent tumor. Int J Radiat Oncol Biol Phys. 2006;65:1514-21.

13. Choy W, Terterov S, Kaprealian TB, et al. Predictors of recurrence following resection of intracranial chordomas. J Clin Neurosci. 2015;22:1792-6.

14. Mitchell A, Scheithauer BW, Unni KK, Forsyth PJ, Wold LE, McGivney DJ. Chordoma and chondroid neoplasms of the spheno-occiput. An immunohistochemical study of 41 cases with prognostic and nosologic implications. Cancer. 1993;72:2943-9.

15. Meis JM, Raymond AK, Evans HL, Charles RE, Giraldo AA. "Dedifferentiated" chordoma. A 
clinicopathologic and immunohistochemical study of three cases. Am J Surg Pathol. 1987;11:516-25.

16. Miettinen M, Karaharju E, Jarvinen H. Chordoma with a massive spindle-cell sarcomatous transformation. A light- and electron-microscopic and immunohistological study. Am J Surg Pathol. 1987;11:563-70.

17. Miettinen M, Wang Z, Lasota J, Heery C, Schlom J, Palena C. Nuclear brachyury expression is consistent in chordoma, common in germ cell tumors and small cell carcinomas, and rare in other carcinomas and sarcomas: an immunohistochemical study of 5229 cases. Am J Surg Pathol. 2015;39:1305-12.

18. Oakley GJ, Fuhrer K, Seethala RR. Brachyury, SOX-9, and podoplanin, new markers in the skull base chordoma vs chondrosarcoma differential: a tissue microarray-based comparative analysis. Mod Pathol. 2008;21:1461-9.

19. Stacchiotti S, Sommer J. Building a global consensus approach to chordoma: a position paper from the medical and patient community. Lancet Oncol. 2015;16:e71-83.

20. Chen KW, Yang HL, Kandimalla Y, Liu JY, Wang GL. Review of current treatment of sacral chordoma. Orthop Surg. 2009;1:238-44.

21. Hsieh PC, Xu R, Sciubba DM, et al. Long-term clinical outcomes following en bloc resections for sacral chordomas and chondrosarcomas: a series of twenty consecutive patients. Spine (Phila Pa 1976). 2009;34:2233-9.

22. Stacchiotti S, Casali PG, Lo Vullo S, et al. Chordoma of the mobile spine and sacrum: a retrospective analysis of a series of patients surgically treated at two referral centers. Ann Surg Oncol. 2010;17:211-9.

23. Fuchs B, Dickey ID, Yaszemski MJ, Inwards CY, Sim FH. Operative management of sacral chordoma. J Bone Joint Surg Am. 2005;87:2211-6.

24. Chen YL, Liebsch N, Kobayashi W, et al. Definitive high-dose photon/proton radiotherapy for unresected mobile spine and sacral chordomas. Spine (Phila Pa 1976). 2013;38:E930-6.

25. DeLaney TF, Liebsch NJ, Pedlow FX, et al. Long-term results of Phase II study of high dose photon/proton radiotherapy in the management of spine chordomas, chondrosarcomas, and other sarcomas. J Surg Oncol. 2014;110:115-22.

26. Rotondo RL, Folkert W, Liebsch NJ, et al. High-dose proton-based radiation therapy in the management of spine chordomas: outcomes and clinicopathological prognostic factors. J Neurosurg Spine. 2015;23:788-97.

27. Chambers PW, Schwinn CP. Chordoma. A clinicopathologic study of metastasis. Am J Clin Pathol. 1979;72:765-76.

28. Baratti D, Gronchi A, Pennacchioli E, et al. Chordoma: natural history and results in 28 patients treated at a single institution. Ann Surg Oncol. 2003;10:291-6.

29. McPherson CM, Suki D, McCutcheon IE, Gokaslan ZL, Rhines LD, Mendel E. Metastatic disease from spinal chordoma: a 10-year experience. J Neurosurg Spine. 2006;5:277-80.

30. Carroll M, Ohno-Jones S, Tamura S, et al. CGP 57148, a tyrosine kinase inhibitor, inhibits the growth of cells expressing BCR-ABL, TEL-ABL, and TEL-PDGFR fusion proteins. Blood. 1997;90:4947-52.

31. Apperley JF, Gardembas M, Melo JV, et al. Response to imatinib mesylate in patients with chronic myeloproliferative diseases with rearrangements of the platelet-derived growth factor receptor beta. N Engl J Med. 2002;347:481-7.

32. Stacchiotti S, Longhi A, Ferraresi V, et al. Phase II study of imatinib in advanced chordoma. J Clin Oncol. 2012;30:914-20.

33. Ferraresi V, Nuzzo C, Zoccali C, et al. Chordoma: clinical characteristics, management and prognosis of a case series of 25 patients. BMC Cancer. 2010;10:22.

34. Du R, Wu S, Lv X, Fang $H$, Wu S, Kang J. Overexpression of brachyury contributes to tumor metastasis by inducing epithelial-mesenchymal transition in hepatocellular carcinoma. J Exp Clin Cancer Res. 2014;33:105.

35. Shalaby A, Presneau N, Ye $\mathrm{H}$, et al. The role of epidermal growth factor receptor in chordoma pathogenesis: a potential therapeutic target. J Pathol. 2011;223:336-46.

36. Stacchiotti S, Tamborini E, Lo Vullo S, et al. Phase II study on lapatinib in advanced EGFR-positive chordoma. Ann Oncol. 2013;24:1931-6.

37. Singhal N, Kotasek D, Parnis FX. Response to erlotinib in a patient with treatment refractory chordoma. Anticancer Drugs. 2009;20:953-5.

38. Asklund T, Sandstrom M, Shahidi S, Riklund K, Henriksson R. Durable stabilization of three chordoma cases by bevacizumab and erlotinib. Acta Oncol. 2014;53:980-4. 
39. Hof H, Welzel T, Debus J. Effectiveness of cetuximab/gefitinib in the therapy of a sacral chordoma. Onkologie. 2006;29:572-4.

40. Linden O, Stenberg L, Kjellen E. Regression of cervical spinal cord compression in a patient with chordoma following treatment with cetuximab and gefitinib. Acta Oncol. 2009;48:158-9.

41. Bompas E, Le Cesne A, Tresch-Bruneel E, et al. Sorafenib in patients with locally advanced and metastatic chordomas: a phase II trial of the French Sarcoma Group (GSF/GETO). Ann Oncol. 2015;26:2168-73.

42. Wilhelm SM, Adnane L, Newell P, Villanueva A, Llovet JM, Lynch M. Preclinical overview of sorafenib, a multikinase inhibitor that targets both Raf and VEGF and PDGF receptor tyrosine kinase signaling. Mol Cancer Ther. 2008;7:3129-40.

43. Chugh R, Dunn R, Zalupski MM, et al. Phase II study of 9-nitro-camptothecin in patients with advanced chordoma or soft tissue sarcoma. J Clin Oncol. 2005;23:3597-604.

44. Chay WY, Teo M, Sittampalam K, Toh HC. Effective use of thalidomide in the treatment of recurrent metastatic chordoma. J Clin Oncol. 2011;29:e477-80.

45. Gaddipati H, Liu K, Pariser A, Pazdur R. Rare cancer trial design: lessons from FDA approvals. Clin Cancer Res. 2012;18:5172-8.

46. Presneau N, Shalaby A, Ye $\mathrm{H}$, et al. Role of the transcription factor $\mathrm{T}$ (brachyury) in the pathogenesis of sporadic chordoma: a genetic and functional-based study. J Pathol. 2011;223:327-35.

47. Nelson AC, Pillay N, Henderson S, et al. An integrated functional genomics approach identifies the regulatory network directed by brachyury (T) in chordoma. J Pathol. 2012;228:274-85.

48. Yang XR, Ng D, Alcorta DA, et al. T (brachyury) gene duplication confers major susceptibility to familial chordoma. Nat Genet. 2009;41:1176-8.

49. Pillay N, Plagnol V, Tarpey PS, et al. A common single-nucleotide variant in $\mathrm{T}$ is strongly associated with chordoma. Nat Genet. 2012;44:1185-7.

50. Wu Z, Wang K, Wang L, et al. The brachyury Gly177Asp SNP is not associated with a risk of skull base chordoma in the Chinese population. Int J Mol Sci. 2013;14:21258-65.

51. Tirabosco R, Mangham DC, Rosenberg AE, et al. Brachyury expression in extra-axial skeletal and soft tissue chordomas: a marker that distinguishes chordoma from mixed tumor/ myoepithelioma/parachordoma in soft tissue. Am J Surg Pathol. 2008;32:572-80.

52. Pinto F, Pertega-Gomes N, Pereira MS, et al. T-box transcription factor brachyury is associated with prostate cancer progression and aggressiveness. Clin Cancer Res. 2014;20:4949-61.

53. Kilic N, Feldhaus S, Kilic E, et al. Brachyury expression predicts poor prognosis at early stages of colorectal cancer. Eur J Cancer. 2011;47:1080-5.

54. Palena C, Roselli M, Litzinger MT, et al. Overexpression of the EMT driver brachyury in breast carcinomas: association with poor prognosis. J Natl Cancer Inst. 2014;106(5). doi:10.1093/jnci/ dju054.

55. Roselli M, Fernando RI, Guadagni F, et al. Brachyury, a driver of the epithelial-mesenchymal transition, is overexpressed in human lung tumors: an opportunity for novel interventions against lung cancer. Clin Cancer Res. 2012;18:3868-79.

56. Hamilton DH, Fernando RI, Schlom J, Palena C. Aberrant expression of the embryonic transcription factor brachyury in human tumors detected with a novel rabbit monoclonal antibody. Oncotarget. 2015;6:4853-62.

57. Fernando RI, Litzinger M, Trono P, Hamilton DH, Schlom J, Palena C. The T-box transcription factor Brachyury promotes epithelial-mesenchymal transition in human tumor cells. J Clin Invest. 2010;120:533-44.

58. Sarkar D, Shields B, Davies ML, Muller J, Wakeman JA. BRACHYURY confers cancer stem cell characteristics on colorectal cancer cells. Int J Cancer. 2012;130:328-37.

59. Huang B, Cohen JR, Fernando RI, et al. The embryonic transcription factor Brachyury blocks cell cycle progression and mediates tumor resistance to conventional antitumor therapies. Cell Death Dis. 2013;4:e682.

60. Triana A, Sen C, Wolfe D, Hazan R. Cadherins and catenins in clival chordomas: correlation of expression with tumor aggressiveness. Am J Surg Pathol. 2005;29:1422-34.

61. Abenoza P, Sibley RK. Chordoma: an immunohistologic study. Hum Pathol. 1986;17:744-7.

62. Yan C, Higgins PJ. Drugging the undruggable: transcription therapy for cancer. Biochim Biophys Acta. 2013;1835:76-85.

63. Hamilton DH, Litzinger MT, Fernando RI, Huang B, Palena C. Cancer vaccines targeting the 
epithelial-mesenchymal transition: tissue distribution of brachyury and other drivers of the mesenchymal-like phenotype of carcinomas. Semin Oncol. 2012;39:358-66.

64. Palena C, Polev DE, Tsang KY, et al. The human T-box mesodermal transcription factor Brachyury is a candidate target for T-cell-mediated cancer immunotherapy. Clin Cancer Res. 2007;13:2471-8.

65. Heery CR, Singh BH, Rauckhorst M, et al. Phase I trial of a yeast-based therapeutic cancer vaccine (GI-6301) targeting the transcription factor brachyury. Cancer Immunol Res. 2015;3:1248-56.

66. Hodge JW, Kwilas A, Ardiani A, Gameiro SR. Attacking malignant cells that survive therapy: exploiting immunogenic modulation. Oncoimmunology. 2013;2:e26937.

67. Gameiro SR, Jammeh ML, Wattenberg MM, Tsang KY, Ferrone S, Hodge JW. Radiation-induced immunogenic modulation of tumor enhances antigen processing and calreticulin exposure, resulting in enhanced T-cell killing. Oncotarget. 2014;5:403-16.

68. Gameiro SR, Ardiani A, Kwilas A, Hodge JW. Radiation-induced survival responses promote immunogenic modulation to enhance immunotherapy in combinatorial regimens. Oncoimmunology. 2014;3:e28643.

69. Bilusic M, Heery CR, Arlen PM, et al. Phase I trial of a recombinant yeast-CEA vaccine (GI-6207) in adults with metastatic CEA-expressing carcinoma. Cancer Immunol Immunother. 2014;63:225-34.

70. Mohebtash M, Tsang KY, Madan RA, et al. A pilot study of MUC-1/CEA/TRICOM poxviral-based vaccine in patients with metastatic breast and ovarian cancer. Clin Cancer Res. 2011;17:7164-73.

71. Ponnelle T, Chapusot C, Martin L, et al. Cellular localisation of survivin: impact on the prognosis in colorectal cancer. J Cancer Res Clin Oncol. 2005;131:504-10.

72. Mita AC, Mita MM, Nawrocki ST, Giles FJ. Survivin: key regulator of mitosis and apoptosis and novel target for cancer therapeutics. Clin Cancer Res. 2008; 14:5000-5.

73. Marioni G, Bertolin A, Giacomelli L, et al. Expression of the apoptosis inhibitor protein Survivin in primary laryngeal carcinoma and cervical lymph node metastasis. Anticancer Res. 2006;26:3813-7.

74. Marioni G, Ottaviano G, Marchese-Ragona R, et al. High nuclear expression of the apoptosis inhibitor protein survivin is associated with disease recurrence and poor prognosis in laryngeal basaloid squamous cell carcinoma. Acta Otolaryngol. 2006;126:197-203.

75. Xu C, Yamamoto-Ibusuki M, Yamamoto Y, et al. High survivin mRNA expression is a predictor of poor prognosis in breast cancer: a comparative study at the mRNA and protein level. Breast Cancer. 2014;21:482-90.

76. Athanassiadou AM, Patsouris E, Tsipis A, Gonidi M, Athanassiadou P. The significance of Survivin and Nectin-4 expression in the prognosis of breast carcinoma. Folia Histochem Cytobiol. 2011;49:26-33.

77. Ambrosini G, Adida C, Altieri DC. A novel anti-apoptosis gene, survivin, expressed in cancer and lymphoma. Nat Med. 1997;3:917-21.

78. Chen C, Yang HL, Chen KW, et al. High expression of survivin in sacral chordoma. Med Oncol. 2013;30:529.

79. Froehlich EV, Rinner B, Deutsch AJ, et al. Examination of survivin expression in 50 chordoma specimens-a histological and in vitro study. J Orthop Res. 2015;33:771-8.

80. Lewis KD, Samlowski W, Ward J, et al. A multi-center phase II evaluation of the small molecule survivin suppressor YM155 in patients with unresectable stage III or IV melanoma. Invest New Drugs. 2011;29:161-6.

81. Giaccone G, Zatloukal P, Roubec J, et al. Multicenter phase II trial of YM155, a small-molecule suppressor of survivin, in patients with advanced, refractory, non-small-cell lung cancer. J Clin Oncol. 2009;27:4481-6.

82. Tolcher AW, Quinn DI, Ferrari A, et al. A phase II study of YM155, a novel small-molecule suppressor of survivin, in castration-resistant taxane-pretreated prostate cancer. Ann Oncol. 2012;23:968-73.

83. Medina PP, Slack FJ. microRNAs and cancer: an overview. Cell Cycle. 2008;7:2485-92.

84. Duan Z, Choy E, Nielsen GP, et al. Differential expression of microRNA (miRNA) in chordoma reveals a role for miRNA-1 in Met expression. J Orthop Res. 2010;28:746-52.

85. Duan Z, Shen J, Yang X, et al. Prognostic significance of miRNA-1 (miR-1) expression in patients with chordoma. J Orthop Res. 2014;32:695-701.

86. Osaka E, Yang X, Shen JK, et al. MicroRNA-1 (miR-1) inhibits chordoma cell migration and invasion by targeting slug. J Orthop Res. 2014;32:1075-82. 
87. Long C, Jiang L, Wei F, et al. Integrated miRNA-mRNA analysis revealing the potential roles of miRNAs in chordomas. PLoS ONE. 2013;8:e66676.

88. Bayrak OF, Gulluoglu S, Aydemir E, et al. MicroRNA expression profiling reveals the potential function of microRNA-31 in chordomas. J Neurooncol. 2013;115:143-51.

89. Zhang Y, Schiff D, Park D, Abounader R. MicroRNA-608 and microRNA-34a regulate chordoma malignancy by targeting EGFR, Bcl-xL and MET. PLoS One. 2014;9:e91546.

90. Kuang L, Lv G, Wang B, Li L, Dai Y, Li Y. Overexpression of adenosine deaminase acting on RNA 1 in chordoma tissues is associated with chordoma pathogenesis by reducing miR125a and miR10a expression. Mol Med Rep. 2015;12:93-8.

91. Zou MX, Huang W, Wang XB, Lv GH, Li J, Deng YW. Identification of miR-140-3p as a marker associated with poor prognosis in spinal chordoma. Int J Clin Exp Pathol. 2014;7:4877-85.

92. Osaka E, Kelly AD, Spentzos D, et al. MicroRNA-155 expression is independently predictive of outcome in chordoma. Oncotarget. 2015;6:9125-39.

93. Zou MX, Huang W, Wang XB, et al. Reduced expression of miRNA-1237-3p associated with poor survival of spinal chordoma patients. Eur Spine J. 2015;24:1738-46.

94. Topalian SL, Hodi FS, Brahmer JR, et al. Safety, activity, and immune correlates of anti-PD-1 antibody in cancer. $\mathrm{N}$ Engl $\mathrm{J}$ Med. 2012;366:2443-54.

95. Topalian SL, Drake CG, Pardoll DM. Targeting the PD-1/B7-H1(PD-L1) pathway to activate anti-tumor immunity. Curr Opin Immunol. 2012;24:207-12.

96. Lipson EJ, Forde PM, Hammers HJ, Emens LA, Taube JM, Topalian SL. Antagonists of PD-1 and PD-L1 in cancer treatment. Semin Oncol. 2015;42:587-600.

97. Keir ME, Butte MJ, Freeman GJ, Sharpe AH. PD-1 and its ligands in tolerance and immunity. Annu Rev Immunol. 2008;26:677-704.

98. Mathios D, Ruzevick J, Jackson CM, et al. PD-1, PD-L1, PD-L2 expression in the chordoma microenvironment. J Neurooncol. 2015;121:251-9.
99. Feng Y, Shen J, Gao Y, et al. Expression of programmed cell death ligand 1 (PD-L1) and prevalence of tumor-infiltrating lymphocytes (TILs) in chordoma. Oncotarget. 2015;6:11139-49.

100. Hegi ME, Diserens AC, Gorlia T, et al. MGMT gene silencing and benefit from temozolomide in glioblastoma. N Engl J Med. 2005;352:997-1003.

101. Marucci G, Morandi L, Mazzatenta D, Frank G, Pasquini E, Foschini MP. MGMT promoter methylation status in clival chordoma. J Neurooncol. 2014;118:271-6.

102. Lee DH, Zhang Y, Kassam AB, et al. Combined PDGFR and HDAC inhibition overcomes PTEN disruption in chordoma. PLOS ONE. 2015;10:e0134426.

103. Wang XF, Qian DZ, Ren M, et al. Epigenetic modulation of retinoic acid receptor beta2 by the histone deacetylase inhibitor MS-275 in human renal cell carcinoma. Clin Cancer Res. $2005 ; 11: 3535-42$.

104. Chun SM, Lee JY, Choi J, et al. Epigenetic modulation with HDAC inhibitor CG200745 induces anti-proliferation in non-small cell lung cancer cells. PLoS One. 2015;10:e0119379.

105. Park J, Thomas S, Munster PN. Epigenetic modulation with histone deacetylase inhibitors in combination with immunotherapy. Epigenomics. 2015;7:641-52.

106. Yamada Y, Lovelock DM, Yenice KM, et al. Multifractionated image-guided and stereotactic intensity-modulated radiotherapy of paraspinal tumors: a preliminary report. Int J Radiat Oncol Biol Phys. 2005;62:53-61.

107. Yamada Y, Laufer I, Cox BW, et al. Preliminary results of high-dose single-fraction radiotherapy for the management of chordomas of the spine and sacrum. Neurosurgery. 2013;73:673-80 (discussion 80). 